\title{
Harry Potter and the Critical gaze: Autonomy pathways in literary response writing
}

\section{Glenn Jackson}

Montpelier High School, Montpelier, Vermont, United States of America

ajjackson7399@gmail.com

https://orcid.org/0000-0001-9668-1629

(Received: 30 June 2020; accepted: 10 May 2021)

\section{Abstract}

Critical literacy studies require both textual reading and a knowledge of power dynamics in context. To achieve in critical literacy, learners need to work with different kinds of knowledge and integrate them. In this paper, I analyse how learners connect representations of social injustice from a popular literary text to issues of social justice in their broader cultural context. I investigate how different forms of knowledge came together in their response to a writing task. The empirical data comes from a critical literary course taught to Grade 8 learners in an English class in the southeastern United States. I offer an analysis of an exemplary essay submitted by a learner. In the analysis, I use concepts from the Legitimation Code Theory (LCT) dimension of Autonomy to show how the essay brought together information from the literary texts and from beyond to support interpretations of the characters' stances on the rights of elves. The analysis highlights how integration of knowledge drawn from imaginary and real contexts meets both the implicit and explicit critical literacy goals of the task. The findings offer a means for understanding how autonomy pathways can support teachers and learners in recognising and realising connections between texts and broader cultural discourses in ways that align with disciplinary literacy practices.

Keywords: English education, English language arts, writing instruction, literary analysis, critical literacy, legitimation code theory, autonomy codes

\section{Introduction}

The study of literature is not only a means for developing reading and writing skills but involves adopting value positions in relation to the social issues represented in the literary texts (Christie \& Humphrey, 2008). Successful literary response requires that learners adopt particular dispositions in relation to the issues in the texts as a way of positioning themselves in relation to issues in the broader culture. When the goal is critical literacy, the study of literature can create opportunities for learners to examine issues about power relations 
between social groups while developing literacy skills used for reading and writing about texts in ways that acknowledge and affirm learners' cultural identities (wa Thiong'o, 1986).

In this study I investigated an attempt at a scaffolded model of critical literacy (Simmons, 2016) that intended to help learners connect representations of social injustice in a popular literary text to issues of social justice in the broader cultural context. In order to understand how critical literacies may be cultivated through classroom discourse, the broader study investigated the dispositions realised in the critical literary response writing of learners in a Grade 8 classroom in the southeastern United States. The essays were the culminating product of a series of lessons designed to facilitate a critique of Harry Potter as a means for similarly analysing and evaluating significant historical figures in relation to issues of social justice in the cultural context.

The Harry Potter novels, written by J. K. Rowling, make up one of the best-selling series in history, and Harry's character has been further introduced to audiences all over the world in the form of a blockbuster movie franchise that encapsulates the entire trajectory of the hero's journey. Harry Potter is a fantasy adventure tale whose title character, a boy wizard, is responsible for saving the world from an evil sorcerer who wants to rid the world of nonmagical beings. But uncritical readings of Harry's character ignore or downplay Harry's role in and attitudes toward elvish enslavement in the texts, and resulting interpretations normalise social injustices. In order to develop critical literacies (Simmons, 2016), the passages chosen for this unit focused on depictions of elfish enslavement in the novels that were used to engage learners in critical reflection on issues of human rights and social justice in their own cultural context.

After a week of analysis, discussion, and joint construction, the series of lessons culminated in an independent writing task that asked learners to compare the views of Harry and his two friends, Hermione and Ron, on the issue of enslavement in the wizarding world of the novels. An example of the character analysis genre (Christie \& Derewianka, 2008), this prompt was designed to elicit evaluations of the characters that positioned the writer in relation to the issues in the texts and in the context. The overall goal of the unit was to help learners identify the ways in which language normalised social injustice in literary fiction and relate these insights to social issues in the broader cultural context.

This analysis systematically investigates the ways in which one learner integrated knowledge from fictional and real-world contexts to successfully demonstrate the critical disposition that was the underlying goal of the classroom unit. Analysing moves between information about the literary text and other sources of knowledge reveals pathways that supported this learner in constructing a critical response that connected text and context. I use concepts from Legitimation Code Theory (LCT) to show how this highly successful writer addressed the stated targets and the implicit goals of the task by evaluating the characters' attitudes towards enslavement in relation to stances towards slavery in the context of United States history. Making these pathways visible offered a means for reflection on and revision of the classroom lessons while demonstrating methods that may be applied in other pedagogic contexts where integration of knowledge from different sources is required. 


\section{Review of the literature}

The study of literature remains a quintessential feature of teaching English as a subject at all levels of schooling (Fang, 2012), and through reading and responding to literary texts, learners come to understand "culturally-valued understandings about life and human behavior" (Christie, 2016, p. 158). From the earliest years of schooling, interpreting stories involves aligning with particular characters' viewpoints and supporting moral evaluations of their actions with evidence from the texts (Rothery \& Stenglin, 2000). Narrative texts, such as the excerpts from the Harry Potter novels of interest here, position readers to adopt particular values in relation to characters and events that are understood to have symbolic meanings (Macken-Horarik, 2003). Literary response requires writers to interpret and explicate these meanings. Literary response writing involves evaluating characters in moral and ethical terms in relation to social and cultural norms, such judgments being the overall purpose of the character analysis genre (Christie \& Derewianka, 2008).

English as a school subject, and the study of literature in particular, has been characterised as the site of an invisible pedagogy based on the cultivation of values and dispositions towards literary texts and the social issues they represent (Christie, 2016; Macken-Horarik, 2006, 2011). Teachers cultivate learners' attitudes towards cultural norms and values through dispositions towards characters and issues in literary texts, and these skills are assessed on standardised assessments. Studies of literary response writing in high-stakes examinations have shown that success requires demonstrating particular attitudes and dispositions toward a variety of texts, phenomena, and ideas using particular forms of expression (Anson, 2017; Christie, 2016; Christie \& Humphrey, 2008; Macken-Horarik, 2006).

What counts as a legitimate interpretation can vary greatly based on the pedagogic context (Jackson, F. 2016), and such qualities are often vague or implicit in classroom instruction and examination writing prompts (Christie \& Humphrey, 2008). Despite many models of literary studies purporting to focus on the learner, interpretations and values tend to be cultivated in ways that align with the views of the teacher (Fairbanks \& Broughton, 2002), or uncritically reproduce the values and ideologies of the status quo (Sleeter \& Stillman, 2005). Through culturally relevant and responsive pedagogy, however, teachers can use particular forms of discourse to guide learners towards interpretations that promote social justice and that critique dominant discourses (Thomas, 2013).

Critical literary response incorporates strategies of "deconstruction, critique and subversion" (Macken-Horarik, 1998, p.75) in order to trouble the ideal reader position established in the narrative (Macken-Horarik, 2003) as well as the connections this makes to discourses in the broader context of culture and pedagogic situation (Macken-Horarik, 2006). Classroom teaching and learning activities can foster critical literacies through an analysis of language choices in texts (Locke \& Cleary, 2011; Macken-Horarik, 1998), with systemic functional linguistics offered as one means of critical literary analysis in classroom contexts (Schleppegrell \& Moore, 2018; Simmons 2016, 2018). Sosa and Bhathena (2019) have shown how personal knowledge and literacies can be leveraged for critical literacy against 
status quo value reproduction in English lessons by helping learners explore the "moral and social values and commitments one brings to making sense of stories and characters" ( $\mathrm{p}$. 224).

From the perspective of Legitimation Code Theory (LCT) (Maton, 2014), the implicit, valueoriented nature of English as a subject is understood as a "cultivated knower code" (Christie, 2016, p. 158); this means that the basis of success is not technical knowledge and procedures, but the demonstration of "personal attitudes and the expression of appropriate values" (Christie, 2016, p. 159). The gradually-developed ability to recognise and realise accepted ways of interpreting and valuing literary texts can be understood as a "cultivated gaze" (Maton, 2014, p. 99), in which dispositions are shaped through interactions with significant knowers - including teachers and other learners-who demonstrate valued ways of knowing (Christie, 2016; Maton, 2014). In literary response, interpretations deemed successful by the teacher or evaluator provide evidence of the gaze cultivated in a particular pedagogic context. In this study, I set out to investigate the ways in which particular patterns of meaning in literary response writing contributed a critical gaze that demonstrated awareness of different stances on issues of power and social justice.

\section{Context of the study}

This study took place in a rural, predominantly white, working class community in the southeastern United States. The middle school was located near the center of a town of 17,000 people and served approximately 900 learners in Grades 6-8 (aged 10-14), more than half of whom qualified for free or reduced-price lunch. At the time of the study, I was the instructional coach at the school and my primary role was to work with teachers to develop disciplinary literacy instructional practices. I intended to conduct a study of knowledgebuilding in middle grade English classrooms, and after responding to a flyer, Dr. Natalie Miller (a pseudonym), a highly skilled veteran teacher with whom I had worked for several years, agreed to participate. Miller was teaching two advanced English classes, and twelve learners in the two classes assented to participation in the study, with parental consent obtained in accordance with IRB guidelines.

The essays I analyse in this study were produced as a result of a curriculum unit made up of lessons carried out over the course of seven instructional days, culminating in two days in which the learners wrote their independent essays. The purpose of the unit was to have learners analyse the stances of various characters on issues of power between groups in literary fiction. In order to do this, learners were guided through a language-focused analysis of two passages from the Harry Potter novel series. The texts were chosen to situate Harry's attitude towards Kreacher, an enslaved elf, in relation to his attitudes towards Hermione and Ron, who hold opposing views on the issue of enslavement.

The lessons were adapted from analyses appearing in the work of Simmons (2012, 2016), who used discourse analysis to help high school learners develop critical literacies through the analysis of culturally significant texts. Simmons's (2016) model of critical literacy guided 
our efforts as we designed and implemented lessons aimed at helping learners analyse the ways in which the author's language choices normalised the practice of enslavement in relation to Harry's character.

We began the unit with small group discussions of Harry Potter book covers and movie posters to introduce the characters, plot, and issue of elvish enslavement in the novels to learners who were unfamiliar with the texts. We then read a two-page passage from Harry Potter and The Deathly Hallows (Rowling, 2007) that depicts Harry, Hermione, and Ron confronting Kreacher, an enslaved elf whom Harry inherited. The scene conveys the characters' mutual loathing as Harry treats Kreacher, as one learner wrote, "without the least bit of compassion" (Text 4). After reading, analysing, and discussing the first passage, Miller facilitated the joint construction of a response paragraph interpreting the power dynamic between Harry and Kreacher in the text. This response interpreted the significance of Kreacher's name, a misspelling that invokes the dehumanizing term "creature" and is compounded by the animalistic description of his appearance and living conditions. This activity involved all learners in writing a critical response paragraph that focused on the power dynamic between the characters and problematised Harry's role as unassailable hero of the story.

The second passage, from Harry Potter and The Goblet of Fire (Rowling, 2000), depicts Hermione introducing the abolitionist Society for the Promotion of Elfish Welfare (SPEW) to Ron and Harry. The characters' conversation demonstrates Hermione's and Ron's opposing stances on the issue, with Ron not only ridiculing the club, but the premise of its goals, as he disturbingly argues that the elves "enjoy being enslaved" (Rowling, 2000, p. 224). When presented with an opportunity to take a firm stance on the side of abolition by endorsing Hermione's organization, Harry remains ambivalent. Despite Harry's apathetic response to Hermione's organization and amusement in response to Ron's explicit endorsement of enslavement, many learners were reluctant to criticise the protagonist in their written responses, indicating resistance to the critical gaze cultivated throughout the unit.

While it was made clear to the class that the analysis of the texts concerned issues that extended beyond Harry Potter, the prompt simply asked learners to "Compare the views of Hermione, Ron, and Harry on the issue of elvish enslavement." Verbal directions explained that learners were to write five paragraphs - one each for Harry, Hermione, and Ron, along with an introduction and a conclusion. Hitting this target determined success or failure when it came to the teacher's scoring of the essays. Within the data set, however, were essays that stood out because they not only provided information from the literary texts but reinforced their analysis of the characters' views by relating them to issues in the world beyond the texts. Writers who made such moves strengthened their evaluations of the characters while also indicating that they understood how broader cultural discourses similarly normalise injustices perpetrated by historical figures.

These movements beyond the content called for in the writing prompt were somewhat surprising but highly valued, with most learners who adopted a critical disposition towards Harry's character incorporating non-target ideas into their writing to strengthen their 
evaluations and position themselves in relation to similar issues in the cultural context. The goal of this study was to uncover the ways in which one high-achieving essay brought together target and non-target information to realise the critical disposition cultivated in the unit, making these highly valued moves more visible, accessible, and open to further critique and refinement. Such an analysis offers a means for understanding the ways in which critical dispositions may be adopted and resisted in classroom writing tasks, with implications for pedagogic practice.

\section{Methodology}

The analysis I describe below is based on a larger doctoral study that used qualitative methods to investigate patterns of meaning in essays written by early secondary learners in response to a task designed to facilitate critical interpretations of literature.

\section{Data Collection}

This study presents an analysis of a single exemplary critical literary response text, written by a learner in a Grade 8 English classroom over the course of two days and in a single typed draft. This essay was one of five responses I analysed for the larger study. The teacher of record felt that this response represented a high level of success with the task, both with regard to the stated writing prompt and to its connections to issues in the broader cultural context. The essay was provided for analysis without identification.

\section{Analytic Framework}

What learners are expected to know and be able to do is a central concern in any teaching and learning situation. Identifying how learning targets are achieved and evaluated in classroom activities can also reveal discrepancies between the stated and implicit goals of a unit, helping to explain why some learners who are unable to pick up on the hidden curriculum struggle while others may be predisposed to better understand the stated and implicit goals of the task. This study offers an analysis of classroom literary response writing to determine what kinds of knowledge were seen as essential to the task, and what kinds were seen as being off-topic, either in ways that contributed to or did not contribute to the purpose of the task. This is accomplished by viewing the essays through the perspective of autonomy codes (Maton \& Howard, 2018) since these illuminate the ways in which different kinds of knowledge are brought together to construct a critical interpretation.

Like other LCT dimensions, Autonomy is made up of two complementary concepts, positional autonomy and relational autonomy. Positional autonomy (PA) refers to the strengths of relations around the content (ideas, entities, etc.) that are considered acceptable in a particular text or context (Maton \& Howard, 2018). In this study, PA describes the degree to which meanings in the texts related to the content were identified in the writing prompt. Relational autonomy (RA) refers to the strengths of relations around what purposes (goals or aims) are considered acceptable in a particular text or context (Maton \& Howard, 2018). In this study, RA describes the degree to which meanings in the text related to the 
intended purpose of the prompt. These concepts work in conjunction with one another to describe the degree to which instances in a text are aligned with the task's content and purpose, or target (Maton \& Howard, forthcoming).

Analysing the ways in which different statements in the texts were more or less related to the target content and purpose of the writing task requires a "language of description" or "translation device" (Bernstein, 2000, p.132) for moving between the theoretical concepts of positional and relational autonomy and the empirical data-the written essays. The translation devices for this study (see Table 1 and Table 2) were adapted from the generic Autonomy translation device introduced by Maton and Howard (2018). This analytic tool allowed for the description of each sentence of each essay in terms of its strength of relations to the targeted content and purpose of the task. In this analysis strengths in positional and relational autonomy are analysed in relation to the target of the classroom task-comparing the characters' views on the issue of enslavement.

Table 1

Specific positional autonomy translation device for this paper

\begin{tabular}{cll}
\hline PA+/- & Coding descriptors & In this analysis \\
\hline+ & $\begin{array}{l}\text { Target: strongly related to } \\
\text { stated content of task }\end{array}$ & $\begin{array}{l}\text { Information about character stances on issues of } \\
\text { social justice in the texts }\end{array}$ \\
\cline { 2 - 3 }$\uparrow$ & $\begin{array}{l}\text { Non-target: } \text { weakly related } \\
\text { to stated content of task }\end{array}$ & $\begin{array}{l}\text { Information not about character stances on issues of } \\
\text { social justice in the texts }\end{array}$ \\
\hline
\end{tabular}

Table 2

Specific relational autonomy translation device for this paper

\begin{tabular}{cll}
\hline$R A+/-$ & Coding descriptors & In this analysis \\
\hline+ & $\begin{array}{l}\text { Target: strongly related to } \\
\text { stated purpose of task }\end{array}$ & $\begin{array}{l}\text { Purpose is to evaluate character stances on issues of } \\
\text { social justice in the texts }\end{array}$ \\
\cline { 2 - 3 }$\uparrow$ & $\begin{array}{l}\text { Non-target: weakly related } \\
\text { to stated purpose of task }\end{array}$ & $\begin{array}{l}\text { Purpose does not evaluate character stances on } \\
\text { issues of social justice in the texts }\end{array}$ \\
\hline
\end{tabular}

The target of an educational practice, conceptualised within the LCT dimension of Autonomy (Maton \& Howard, 2021), involves two aspects: the constituents (i.e., content) of a given practice; and the principles (i.e., purposes) to which these are applied. Identifying the target of a pedagogic practice involves establishing the perspective from which the situation is viewed since different actors may see different objectives in a particular situation and therefore call on different kinds of content. In this case, the teacher's perspective was taken since it was this perspective that would ultimately determine the relative achievement of the written responses as provided through evaluation and feedback. 
From the teacher's perspective, the writing prompt determined what was essential for the task, and the prompt directed learners to the evaluation of characters' views of elvish enslavement in the literary texts. The autonomy analysis focuses on the ways in which the essays related to the writing prompt as a means of illuminating different kinds of knowledge that were more strongly or weakly related to this target. Therefore, when the focus of the writing is on the literary text, the PA is stronger $(\mathrm{PA}+)$ because the content comes from within the target. When the focus of the learner's writing is on content from beyond the literary text, the PA is weaker (PA-). Similarly, when the writing is turned towards the intended purpose of the writing task, the RA is stronger (RA+), and when information is turned towards purposes other than that stated in the writing prompt, the RA is weaker (RA-). Analysing the texts to determine the ways in which essays move between different coding orientations can reveal pathways between target and non-target knowledge that help learners demonstrate critical gazes towards the texts.

Figure 1

Autonomy Plane with Descriptions of Coded Data

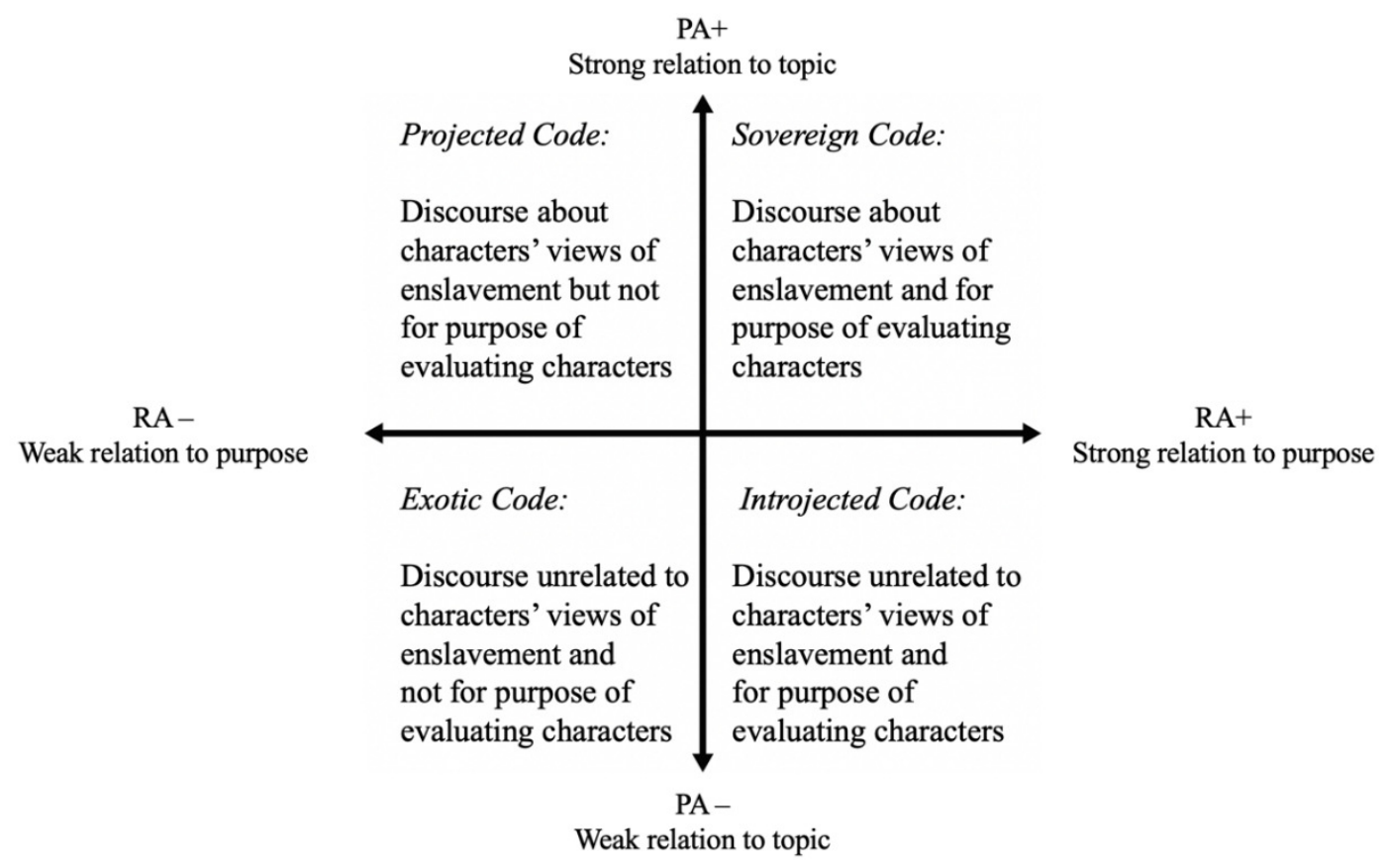

Taking different strengths of each relation into account creates four coding orientations. These autonomy codes can be represented on a topological plane (Maton \& Howard, 2018; see Figure 1). As represented on the plane in Figure 1, discourse that was focused on the characters' views on elvish enslavement may be identified as part of the sovereign code, meaning it is clearly on-topic with regard to both content and purpose $(\mathrm{PA}+\mathrm{RA}+)$. The projected code involves meanings that turn the content of the task to a non-targeted purpose (PA+, RA-). This occurred when information that was actually related to the intended content failed to contribute to the overall goal of the task or achieved a different purpose. The exotic code refers to discourse that is aligned with neither the stated content nor the intended purpose of the lesson (PA-, RA-), unrelated to the topic. This occurs when information from outside the targeted content fails to contribute to the text's specific purpose. Finally, the 
introjected code (PA-, RA+) refers to information from beyond the targeted content but turned to the intended purpose. Movements around the plane indicate shifts within a stretch of discourse that are closer to or further from the target of the lesson. In this writing task, movements beyond the sovereign code proved the distinguishing factor of the most highachieving response.

These translation devices provided a heuristic for describing the ways in which meanings in the texts moved between ideas that related more or less directly to the target content and purpose of the task. Coding the entire data set in terms of the relative strength of PA and RA allowed for a detailed description of the pathways between different codes in the essays. Below, I discuss the ways in which one high-achieving essay went beyond the sovereign code of the writing prompt and source texts to demonstrate a critical literary gaze that connected text and context.

\section{Findings}

Writing in response to literature requires learners to demonstrate that they understand the symbolic interpretation of the text valued in the pedagogic situation and context of culture (Christie \& Dreyfus, 2007; Macken-Horarik, 2006). For this particular task, essays that remained in the sovereign code and focused only on the source texts were viewed by the teacher as less successful than essays that supported interpretations of the literary texts with references to related historical and cultural knowledge. Bringing in information from beyond the literary passages and writing prompt allowed learners to strengthen their evaluations of the characters and situate issues of social justice in the texts within a context of actual historical events. While these non-target pathways were not always turned back to the purpose of the task, they were the distinguishing factor of the most highly rated texts in the data set.

In the classroom activities that produced this essay, discussions about the class's analysis of the passages frequently integrated knowledge from the fictional literary texts with relevant historical knowledge. Therefore, we did not find it entirely surprising that all essays contained at least one reference to information from beyond the source texts and writing prompt. There were stark differences, however, in the frequency of references beyond the texts in different essays and the ways in which these supported critical evaluations of Harry's character.

While sovereign code statements that directly addressed the prompt made up the vast majority of all essays, the most high-achieving learners more frequently brought in knowledge from elsewhere to support their analysis of each character. These moves were identified by Miller as attempts by the writers to demonstrate an awareness of the ways in which cultural and historical issues related to the representations of enslavement and oppression in the novels. While all writers attempted such moves at least once, the most highly rated essay included considerably more non-target references than any other text in the data set. The analysis below describes instances of non-target information in pathways that 
went beyond the sovereign code of the writing task. These are identified by lower-case letters in the figures. In this analysis, each point on the plane indicates a coded sentence or clause, with pathways represented by connected line segments.

The text analysed here is the only essay in the data set to begin outside the sovereign code. This pathway involves a single non-target instance (a) made up of two sentences, which are both concerned with general issues of morality and individual choice (Figure 2). These statements are never connected with the targeted content or purpose since the next sentence jumps abruptly to the sovereign code in order to introduce the topic that the essay will discuss - the "ongoing debate concerning the injustice and exploitation against the house elves" (Text 5, para. 1). This initial non-target move exemplifies what we might call a oneway trip into the exotic code (Maton \& Howard, 2018), which does not directly contribute to the overall goals of the writing task.

Figure 2

Non-target Pathway in Paragraph 1 of High Achieving Essay (Text 5)

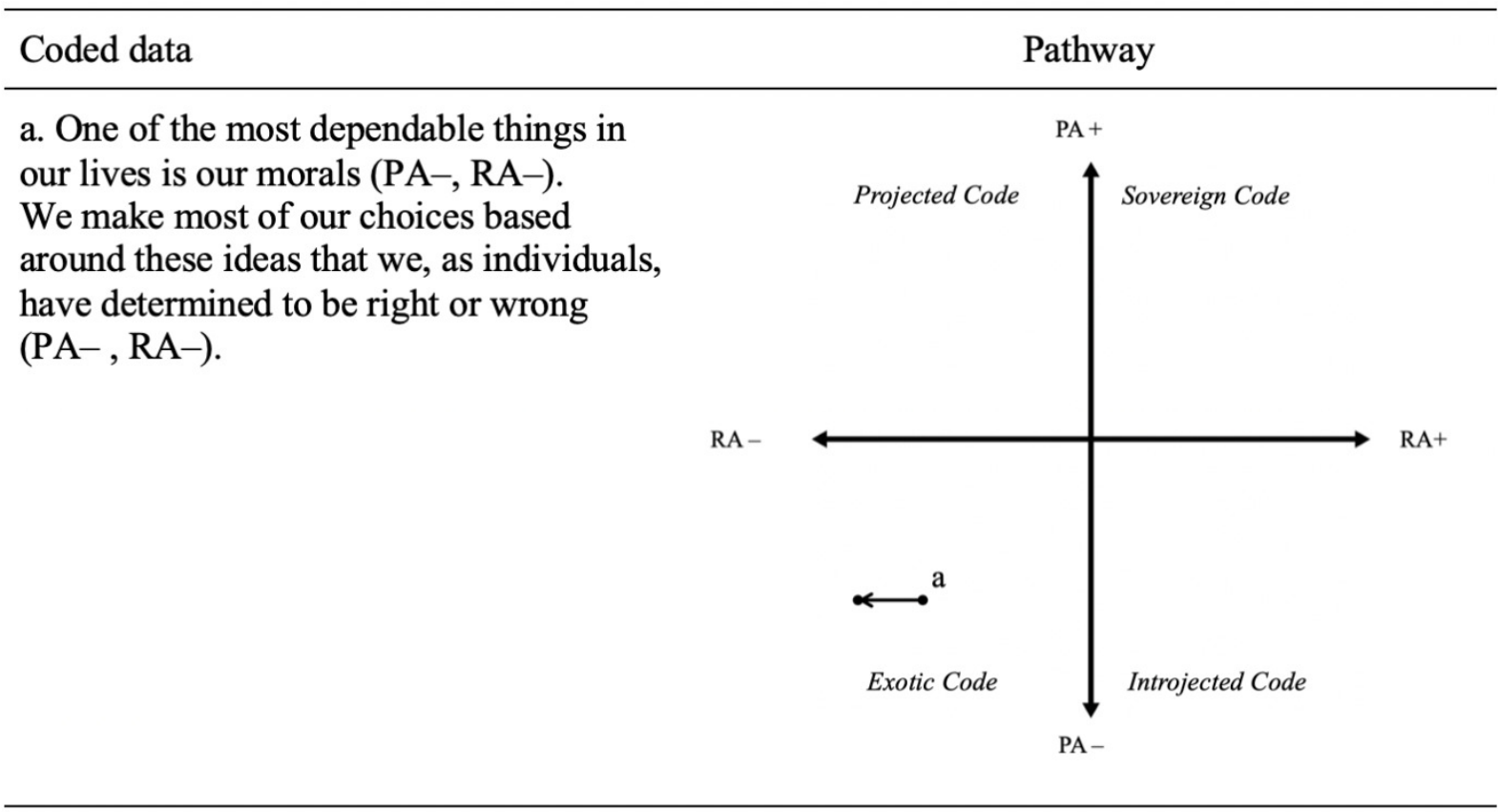

The next instances of non-target information occur in the second paragraph when the writer discusses Hermione's views on elvish enslavement (Figure 3). This autonomy pathway involves two different 'moves' (identified as $b$ and $c$ in Figure 3), which relate the character to distinct constituents of non-target knowledge, 'J. K. Rowling' and 'abolitionists in American history.' The statements in the first non-target move (b) establish Hermione's female gender as a factor in Rowling's decision to cast Hermione as helping the elves "overcome these prejudicial judgments" related to elvish enslavement. The writer supports this idea using additional non-target information, claiming that Rowling "is known for conquering stereotypes in her male dominated career field," and moving farther away from the targeted content and purpose of the prompt. This information is then connected back to the purpose of the prompt as the mention of "righteousness and tolerance" reinforces Hermione's position on the side of abolition. 
Figure 3

Non-target Pathways in Paragraph 2 of High Achieving Essay (Text 5)

\section{Coded data}

b. The author could have just as easily chosen one of the male characters to overcome these prejudicial judgments, however J. K. Rowling selected Hermione in particular (PA-, RA+). The author is known for conquering stereotypes in her male dominated career field $(\mathrm{PA}+, \mathrm{RA}+)$, so it is logical that she appointed the female protagonist to take a stand for righteousness and tolerance $(\mathrm{PA}-, \mathrm{RA}+)$.

c. Hermione resembles abolitionists in American history who started a movement to extinguish enslavement of African Americans (PA-, $\mathrm{RA}+$ ). She is willing to sacrifice everything she has worked diligently to achieve, to ensure a fair treatment for the "shockingly unrepresented" house elves (PA+, RA+).
Pathway

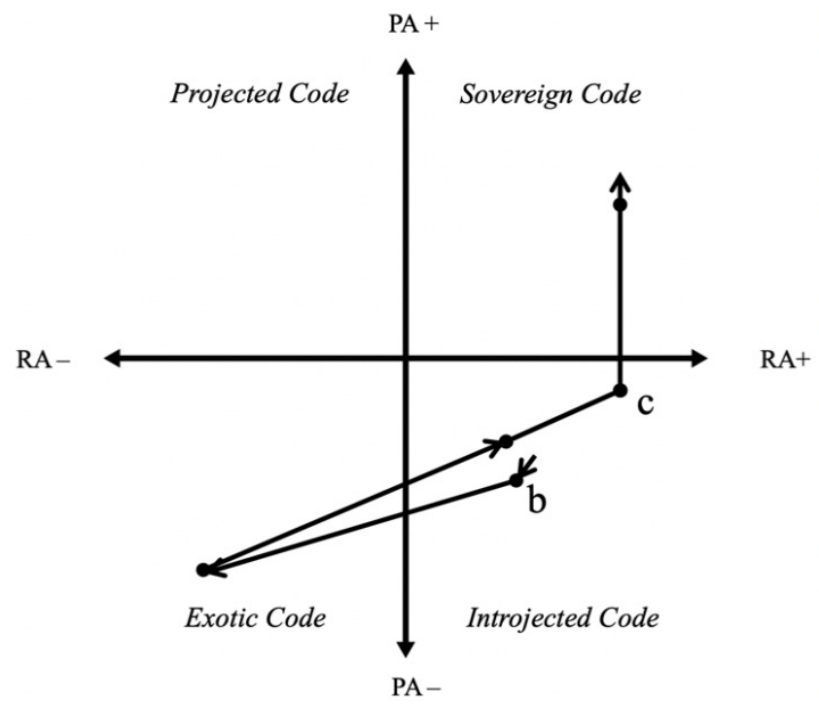

The next sentence introduces more non-target information (c) through a comparison between Hermione and abolitionists from history. This statement remains in the introjected code and contributes strongly to the purpose of evaluating Hermione's character while remaining relatively closely associated with the targeted content. While not entirely cohesive, the references work together to compare Hermione favourably with entities cast as overcoming gender discrimination and fighting to end the enslavement of African Americans. This relatively effective non-target pathway was boosted by the connections with sovereign code information before and after the statements, indicated by the small arrows at the beginning and end of the pathway.

The writer's analysis of Ron also includes a non-target pathway involving a comparison between the character's views and information related to the history of slavery and its legacy in the United States (Figure 4). This instance arises from sovereign code information about Ron's views that is reinforced by this comparison to a culturally significant non-target entity. In this non-target move (d), the writer compares Ron to "privileged white men during the civil rights era," (Text 5, para. 3), a comparison that positions both Ron and the dominant culture, represented in this symbolic image, in a negative light. This return trip was another example of turning non-target information to purpose in a way that demonstrated an awareness of connections to the broader cultural issue while aligning a character with negatively evaluated dominant discourses, demonstrating the disposition valued in the classroom context. 
Figure 4

Non-target Pathway in Paragraph 3 of High Achieving Essay (Text 5)

Coded data

Pathway

d. In comparison to American history, Ron is similar to privileged white men during the civil rights era in the southeastern United States (PA-, RA+). If the issue of enslavement and bigotry does not negatively affect him, Ron is not going to do anything to stop it (PA+, RA+).

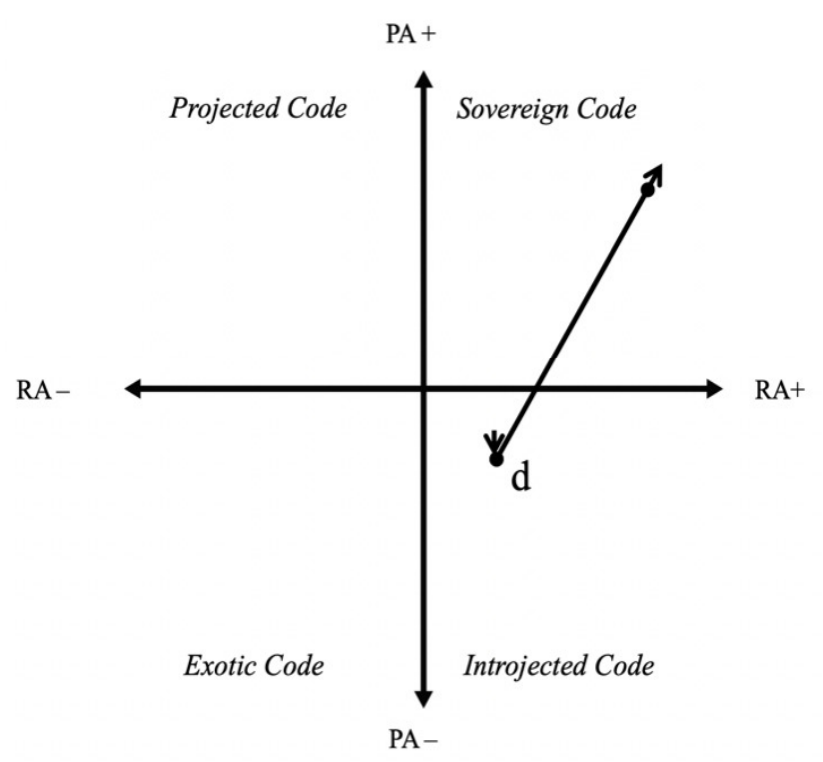

The writer of Text 5 offers a nuanced interpretation of Harry's character, accounting for both positive (e.g., freeing Dobby) and negative (e.g., loathing Kreacher) actions and ideas. Elsewhere in the paragraph, the writer explicitly aligns Harry with Ron's perspective on the issue and against Hermione's abolitionist position. Later, in the single non-target move in the paragraph (e), the writer directly addresses Harry's inconsistent treatment of and attitude towards the two elves, comparing Harry to "slave owners" from American history. Just before this reference, the writer acknowledges Harry's freeing of Dobby, but argues that this experience reinforces his "sense of supremacy over the creatures" (Text 5, para. 4). It is here that the writer chooses to compare Harry to "slave owners" as a means of refuting the argument that freeing Dobby puts Harry on the side of abolition. In the next sentence, the author "directly relates" this idea back to Harry's treatment of the elves. This pathway is represented in Figure 5 and indicates ways in which the non-target reference is situated within the introjected code, but was strongly connected back to the sovereign code. 
Figure 5

Non-target Pathways in Paragraph 4 of High Achieving Essay (Text 5)

Coded data

Pathway

e. In American history, slave owners have freed African Americans, without being an abolitionist completely against the idea of slavery (PA- , RA-). This directly relates with Harry's point of view on emancipating Dobby, but tyrannizing other house elves to an extent $(\mathrm{PA}+, \mathrm{RA}+)$.

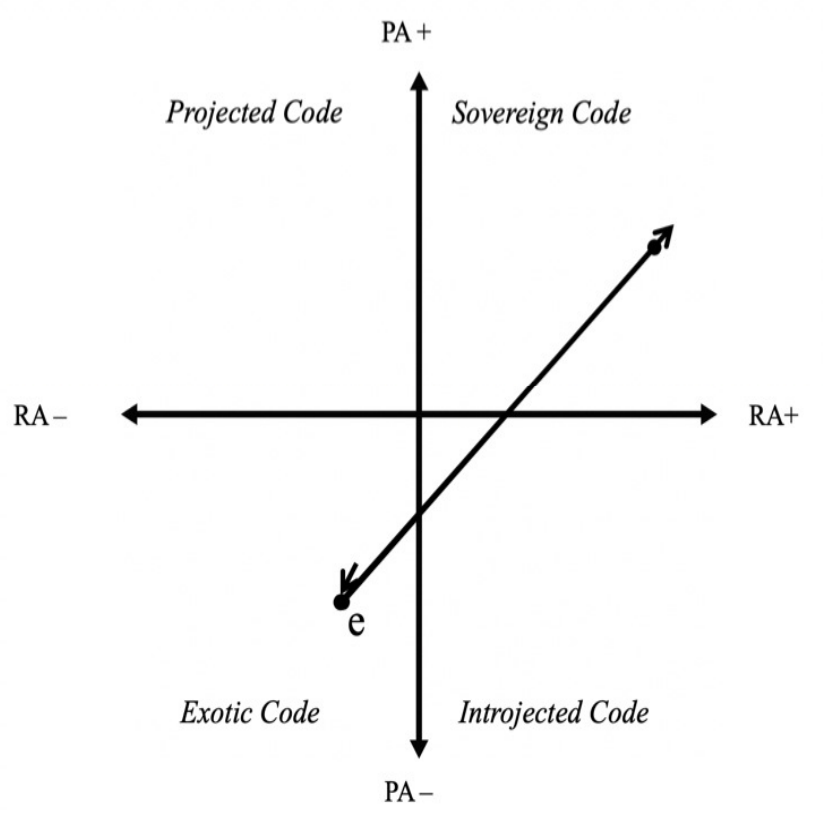

The concluding paragraph included one somewhat disconnected venture beyond the sovereign code, including stops in three codes (Figure 6). After summarizing each character's position on the issue, the writer qualifies the critique of Harry and Ron, which has been extremely sharp to this point in the essay. In a smooth, cohesive move that invokes the positions described in the previous sentences, the writer clarifies that Harry's and Ron's views should not be judged as harshly as Voldemort's, who is then compared to Hitler (f). The next statement remains in the exotic code, and a step nearer the target, and is not clearly related to the sentence before or after $(\mathrm{g})$. The writer again invokes the connection between the enslavement of elves in the novels and the enslavement of African Americans in history, but reference is never connected back to the targeted content or purpose of the prompt and is not cohesively linked with the next sentence. 
Figure 6

Non-target Pathways in Paragraph 5 of High Achieving Essay (Text 5)

Coded data Pathway

f. Even with this belief, Ron and Harry still do not fall to the level of Voldemort (PA+, $\mathrm{RA}+$ ), who resembles the infamous Adolf Hitler (PA-, RA+), who almost succeeded in wiping out the entire Jewish race through mass murder during the second world war (PA-, RA -).

g. The exploitation of the house elves makes several connections to the enslavement of African Americans (PA-, RA-).

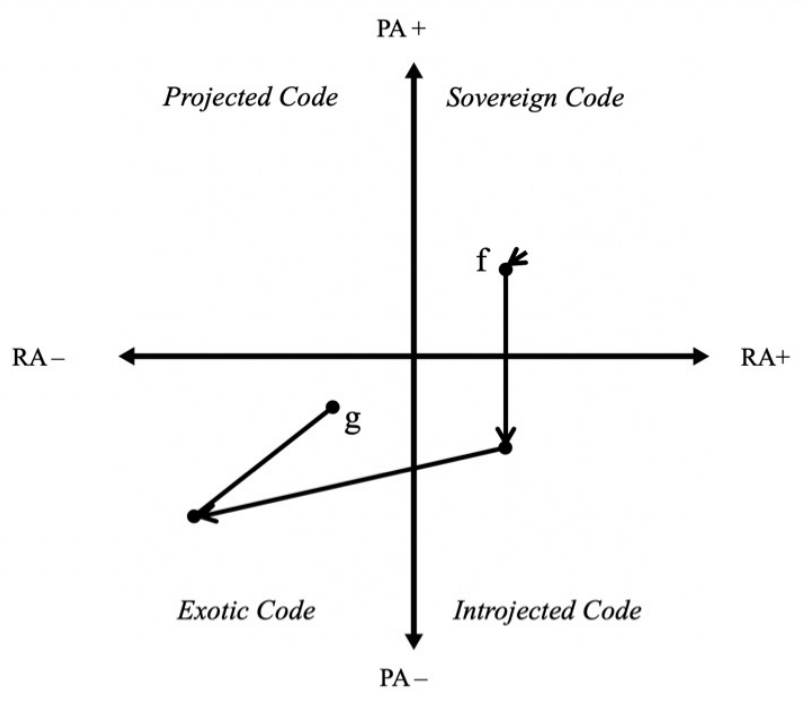

The pathways described above demonstrate the writer's emerging ability to integrate nontarget information effectively into their writing while still addressing the target of the writing task. While the introduction and conclusion included less successful trips into the exotic code, the essay contained several examples of the effective use of information from beyond the prompt to support their analyses of the characters. These pathways beyond the sovereign code were highly valued by the teacher since they demonstrated an awareness of the connections between the issues and value positions in the literary texts and broader cultural discourses related to issues of human rights and social justice.

\section{Discussion}

The critical aspects of this literary response task involved an examination of texts in context, and this required that knowledge from different sources be brought together for the purpose of interpreting and evaluating the characters. While learners whose essays more strictly adhered to the sovereign code were able to satisfy the requirements of the assignment, they were less successful at conveying the implications of the characters' views. Therefore, they were also less successful at demonstrating the critical gaze that positioned the writer on the right side of the real-world issues of social justice represented in the fictional texts.

Miller and I viewed a resistant reading of Harry's character in relation to issues of social justice as a critical interpretation not only because it challenged Harry's positioning as a 'good guy' in the story, but because it also cultivated a disposition critical of analogous viewpoints in our cultural context. In particular, class discussions explicitly connected the value positions taken by the characters in the fantasy novels to positions on human rights and social justice taken by enslavers and segregationists who persist as positively valued figures 
in the dominant culture, as evidenced by the resistance to taking down monuments that normalise social injustices.

Teaching this kind of critical reading of the text in this context depended on keeping these connections to cultural issues outside the official learning targets of the unit. Therefore, the task did not explicitly call for a critical stance towards the characters, and the gaze intended by the unit remained invisible. We hoped, however, that the learners' written responses would exemplify the critical gaze that had been cultivated throughout the unit. The analysis of the essays found that writers who were most critical of Harry tended to address relevant information from the passages more thoroughly, but that these learners also tended to connect details from the text directly to the associated cultural issues discussed in class.

The analysis revealed that these non-target pathways played an important role in helping this highly valued text achieve its purpose because even when not effectively turned to purpose, these attempts at using non-target knowledge for targeted purposes indicated the gaze cultivated in the unit. While all essays in the data set moved between target and non-target knowledge at least once, the frequency and relative effectiveness with which the writer ventured beyond the sovereign code was a distinguishing factor of this and other highly valued essays. Some learners were able critique Harry without going beyond the sovereign code but using non-target information allowed some learners to demonstrate an expanded gaze, one that accounted for connections to issues of social justice in the world beyond the texts. While several essays did not adopt critical orientations to Harry's character, the instances of non-target information elsewhere in the essays showed the writer's awareness of the ways in which the text related to broader issues of social justice and human rights. From the teacher's perspective, even one-way trips away from the writing prompt demonstrated emerging capacities to connect issues in the text with broader cultural and historical events, themes, and value positions.

\section{Conclusion}

This study indicates the need for research into learners' understandings of what specialised ways of thinking the tasks require of them, particularly with regard to critical pedagogy that examines inequalities of power relations between groups. Better understanding the ways in which learners use target and non-target information in their writing to position themselves in relation to social issues can assist instructors in facilitating classroom talk and writing that fosters dispositions aligned with social justice. Maton and Howard (2018) suggested that learners may "possess different capacities to recognise and generate autonomy pathways required for success" (p. 31). This analysis revealed pathways that can now be intentionally planned for in classroom discourse to help learners develop such capacities. Making these pathways visible offers a means of opening up classroom dialogue that can support learners in understanding the ways in which their interpretations of literature align and disalign with value positions related to real world social issues. Further research is necessary for understanding how making the autonomy pathways visible in classroom activities may help 
scaffold learners' abilities to analyse texts critically in relation to culturally relevant issues and ideas.

\section{References}

Anson, D. (2017). Examining the examiners: The state of senior secondary English examinations in Australia. Australian Journal of Language and Literacy, 40(2), 135145.

Bernstein, B. (2000). Pedagogy, symbolic control and identity: Theory, research, critique (Revised ed.). Rowman \& Littlefield.

Christie, F. (2016). Secondary school English literary studies: Cultivating a knower code. In K. Maton, S. Hood, \& S. Shay (Eds.), Knowledge-building: Educational studies in Legitimation Code Theory (pp. 158-175). Routledge.

Christie, F., \& Derewianka, B. (2008). School discourse: Learning to write across the years of schooling. Continuum.

Christie, F., \& Dreyfus, S. (2007). Letting the secret out: Successful writing in secondary English. Australian Journal of Language and Literacy, 30(3): 235-247.

Christie, F., \& Humphrey, S. (2008). Senior secondary English and its goals: Making sense of 'the journey.' In L. Unsworth (Ed.), New literacies and the English curriculum: Multimodal perspectives (pp. 215-237). Continuum.

Fang, Z. (2012). Language correlates of disciplinary literacy. Topics in Language Disorders, 32(1), 19-34.

Fairbanks, C. M., \& Broughton, M. A. (2002). Literacy lessons: The convergence of expectations, practices, and classroom culture. Journal of Literacy Research, 34(4), 391-428.

Jackson, F. (2016). Unraveling high school English literature pedagogic practices: A Legitimation Code Theory analysis. Language and Education, 30(6), 536-553.

Locke, T., \& Cleary, A. (2011). Critical literacy as an approach to literary study in the multicultural, high-school classroom. English Teaching: Practice and Critique, 10(1), 119-139.

Macken-Horarik, M. (1998). Exploring the requirements of critical school literacy: A view from two classrooms. In F. Christie \& R. Mission (Eds.), Literacy and schooling (pp. 74-103). Routledge.

Macken-Horarik, M. (2003). Appraisal and the special instructiveness of narrative. Text, 23(2), 285-312. 
Macken-Horarik, M. (2006). Knowledge through 'know-how': Systemic functional grammatics and the symbolic reading. English Teaching: Practice and Critique, 5(1), $102-121$.

Macken-Horarik, M. (2011). Building a knowledge structure for English: Reflections on the challenges of coherence, cumulative learning, portability and face validity. The Australian Journal of Education, 55(3), 197-213.

Maton, K. (2014). Knowledge and knowers: Towards a realist sociology of education. Routledge.

Maton, K., \& Howard, S. K. (2018). Taking autonomy tours: A key to integrative knowledgebuilding. LCT Centre Occasional Papers, 1, 1-35.

Maton, K. \& Howard, S. K. (2021) Targeting science: Successfully integrating mathematics into science teaching. In K. Maton, J. R. Martin, and Y. J. Doran (Eds.) Teaching science: Knowledge, language, pedagogy (pp.23-48). Routledge.

Rothery J., \& Stenglin, M. (2000). Interpreting literature: The role of appraisal. In L. Unsworth (Ed.), Researching language in schools and communities: Functional linguistic perspectives (pp. 222-244). Cassell.

Rowling, J. K. (2002). Harry Potter and the goblet of fire. New Scholastic.

Rowling, J. K. (2007). Harry Potter and the deathly hallows. Arthur A. Levine Books.

Schleppegrell, M., \& Moore, J. (2018). Linguistic tools for supporting emergent critical language awareness in the elementary schools. In R. Harman (Ed.), Bilingual learners and social equity. Critical approaches to systemic functional linguistics (pp. 23-43). Springer.

Simmons, A. M. (2012). A word in the hand: Supporting critical literacy through a discourse analysis of fantasy, canonical, and nonfiction texts (Unpublished doctoral dissertation). The University of Georgia, Athens, GA.

Simmons, A. M. (2016) Supporting critical literacy in high school English by using systemic functional linguistics to analyse fantasy, canonical, and nonfiction texts. Critical Inquiry in Language Studies, 13(3), 183-209.

Simmons, A. M. (2018). Student use of SFL resources on fantasy, canonical, and non-fiction texts: Critical literacy in the high school ELA classroom. In R. Harman (Ed.), Bilingual learners and social equity: Critical approaches to systemic functional linguistics (pp. 71-90). Springer.

Sleeter, C. \& Stillman, J. (2005). Standardizing knowledge in a multicultural society. Curriculum Inquiry, 35(1), 27-46. 
Sosa, T. \& Bhathena, C. D. (2019). How students use their cultural and linguistic knowledge to transform literacy goals. High School Journal, 102(3), 210-227.

Thomas, E. E. (2013). Dilemmatic conversations: Some challenges of culturally responsive discourse in a high school English classroom. Linguistics and Education 24, 328-347.

wa Thiong'o, N. (1986). Decolonising the mind: The politics of language in African literature. Heinemann. 